$[5]$

\title{
The europium anomaly of seawater: implications for fluvial versus hydrothermal REE inputs to the oceans
}

\author{
Annette M. Olivarez and Robert M. Owen ${ }^{\mathrm{b}}$ \\ a Department of Earth Sciences, The Lniversity of Notre Dame, Notre Dame, IN 46556. LS.1 \\ ${ }^{\mathrm{b}}$ Department of Geological Sciences, The Lniversity of Michigan. Ann Arbor, MI 4810\%, CSA
}

(Received March 13, 1990; revised and accepted March 7, 1991)

\begin{abstract}
Olivarez, A.M. and Owen, R.M., 1991. The europium anomaly of scawater: implications for fluvial versus hydrothermal REE inputs to the oceans. Chem. Geol., 92: 317-328.

Seafloor hydrothermal vent fluids are characterized by rare earth element (REE) enrichments and large positive Eu anomalies; however, this input is not recorded by seawater. Hydrothermal sediments from the southeast Pacific (DSDP Site .598) were examined to address this discrepancy between the observed and predicted REE pattern of seawater. "Scavenging indices", which reflect long-term REE scavenging by iron-rich hydrothermal precipitates, were calculated for each of cight REE's. Comparisons between these indices and the REE content of seawater indicate that the intensity of REE scavenging by hydrothermal precipitates is proportional to the concentration of REE's in the fluid phase. We predict that REE"s are rapidly scavenged from hydrothermal solutions, and that Eu is removed disproportionately faster relative to its neighbors. Eu-anomaly values for Site 598 and other hydrothermal sediments support this prediction: a vent signature is recorded in sediments closest to the ridge axis and the Eu-anomaly values become more seawater-like with increasing distance and scavenging. This implies that the REE content of seawater cannot be used to constrain hydrothermal versus fluvial fluxes to the oceans.
\end{abstract}

\section{Introduction}

The relative importance of various sources of rare earth elements (REE's) to the oceans has been of interest since Piper (1974) first calculated a mass balance for these elements in the marine environment. Although there is general agreement that rivers are the dominant source of REE's, estimates of fluxes from rivers and other sources have varied considerably. For example, early calculations for rivers (e.g., Piper, 1974) were based on limited data and assumed a simple and direct transfer of dissolved fluvial REE's to the pelagic environment. The only measurements of REE's in river waters available to Piper (1974) were those reported for the Gironde River (Høgdahl et al.,
1968 ); thus he was forced to assume that these were representative of world average values. Subsequent investigations indicate that fluvial input processes are complicated: for example, the assumption of direct REE transfer from rivers to oceans is an oversimplification. Both field (Martin et al., 1976; Goldstein and Jacobsen, 1988) and laboratory (Hoyle et al., $1984)$ studies have shown that a significant portion (60-90\%) of REE's in river waters are removed in estuaries, probably through a combination of sorption and co-precipitation reactions (Fleet, 1984). Moreover, Hoyle et al. (1984) have suggested that estuarine removal processes tend to attenuate any initial differences in fluvial REE concentrations, such that rivers with a relatively high initial REE content are likely to experience a greater degree of 
REE removal in estuaries compared to rivers with a lower initial REE content.

The recognition that substantial amounts of dissolved REE's are removed in estuaries implies that REE inputs from non-riverine sources comprise a proportionally greater contribution to the total input. Some authors (Fleet, 1984; Goldstein and Jacobsen, 1988) have suggested that hydrothermal REE inputs may be important in this regard. Measurements of REE concentrations in hydrothermal vent fluids have been determined from samples collected along the East Pacific Rise at $13^{\circ} \mathrm{N}$ and $21^{\circ} \mathrm{N}$ (Michard et al., 1983; Michard and Albarède, 1986), the Juan de Fuca Ridge (Hinkley and Tatsumoto, 1987), and at the mark site along the Mid-Atlantic Ridge at $23^{\circ} \mathrm{N}$ (Campbell et al., 1988). In all cases the hydrothermal fluids were found to be significantly enriched in REE's $\left(10-10^{4}\right.$ times ambient seawater concentrations ) and exhibited a pronounced, positive Eu anomaly. Based on these findings, it is possible that hydrothermal fluids may represent a significant secondary source of REE's (especially Eu) to the oceans.

The present study is concerned with the fate of Eu and other REE's in hydrothermal fluids and, in particular, with the question of whether or not hydrothermal Eu inputs contribute significantly to the total mass of $\mathrm{Eu}$ in seawater. Recently, Goldstein and Jacobsen (1988) have suggested that a discrepancy exists between the amount of Eu in seawater and the predicted amount based on calculated $\mathrm{Eu}$ inputs from river and hydrothermal sources. If it is assumed that REE's from vent fluids (which are characterized by high positive Eu anomalies ) are directly transferred to seawater, and that $\mathrm{Eu}$ is removed at the same rate as its nearest neighbors in the lanthanide series, then the combined REE flux from both rivers and hydrothermal solutions should result in a significant positive Eu anomaly for the REE pattern of seawater. The problem, as identified by Goldstein and Jacobsen (1988), is that, although the concentration of REE's varies both within and between ocean basins (Elderfield and Greaves, 1982; De Baar et al., 1983, 1985), no positive Eu anomaly of the expected magnitude has been observed. Goldstein and Jacobsen (1988) suggest that this discrepancy implies that the measurements of $\mathrm{Eu}$ in vent fluids are not representative of hydrothermal solutions in general, and/or, there is some unknown source of REE's to the oceans which is depleted in $\mathrm{Eu}$. This would tend to attenuate the effect of hydrothermal Eu inputs on the REE pattern of seawater. A third possibility is that there are significant inaccuracies in the values they used to compute the mass flux of dissolved REE's entering the ocean from rivers. The last possibility is suggested because the riverine REE flux values they report are based upon estimates of REE removal in estuaries. Any one of these possibilities, if valid, has significant implications for our understanding (or lack thereof) of the marine geochemical cycle of the REE's.

The present study indicates that this discrepancy is actually due to a false assumption concerning the fate of REE's in hydrothermal fluids. In an analogous sense to what Goldstein and Jacobsen (1988) have shown to be the case for rivers, the quantitative significance of hydrothermal REE inputs to the ocean does not depend on the amounts that are originally present in the hydrothermal fluid, but, instead, is highly dependent upon their ability to escape removal processes and become incorporated into seawater. Previous work has shown that the Fe-rich oxyhydroxide precipitates which form when hydrothermal fluids mix with seawater are highly efficient scavengers of REE's (Ruhlin and Owen, 1986a, b). In this study we have used the REE composition of hydrothermal sediments to estimate the relative degree of REE scavenging from the fluid phase and to show that, in the presence of excess $\mathrm{Fe}$, the intensity of REE scavenging is proportional to the original REE concentrations in the fluid. These results support our previous argument that REE scavenging from hydro- 
thermal fluids is both rapid and extensive (Olivarez and Owen, 1989). If Eu (and other REE's) in hydrothermal fluids are prevented from entering seawater because of this scavenging process, then there is no reason to expect that the seawater REE pattern should exhibit a positive Eu anomaly. We suggest that the positive Eu anomaly predicted by Goldstein and Jacobsen (1988) does occur, but that it is manifested by hydrothermal sediments rather than seawater.

\section{Methods}

The 50 samples analyzed in this study were obtained from the Deep Sea Drilling Project (DSDP) Site $598\left(19^{\circ} 0.282^{\prime} \mathrm{S}, 124^{\circ}\right.$ $40.606^{\prime} \mathrm{W}$ ). Site 598 comprises a $43 \mathrm{~m}$ column of sediments which represents a complete record of hydrothermal sedimentation along the western flank of the EPR during the past 16 Myr and over paleo-distances ranging from 9 to $1150 \mathrm{~km}$ from the ridge axis. The geochemical data used in this study were obtained by instrumental neutron activation analysis (INAA) at the Phoenix Memorial Laboratory, The University of Michigan, using standard INAA procedures (Gordon et al., 1968; Dams and Robbins, 1970). A detailed description of the procedures used to analyze these samples, including the geochemical and mass accumulation rate data, are given in Ruhlin and Owen (1986a, b). Statistical analyses of the chemical data were performed using MIDAS, a package of computer programs provided by the Statistical Research Laboratory at The University of Michigan (Fox and Guire, 1976).

\section{Results and discussion}

\subsection{The Eu discrepancy and its implications}

A comparison of the shale-normalized REE patterns of average seawater, rivers, and hydrothermal vents (Fig. 1) illustrates the $\mathrm{Eu}$ discrepancy problem as discussed by Gold-

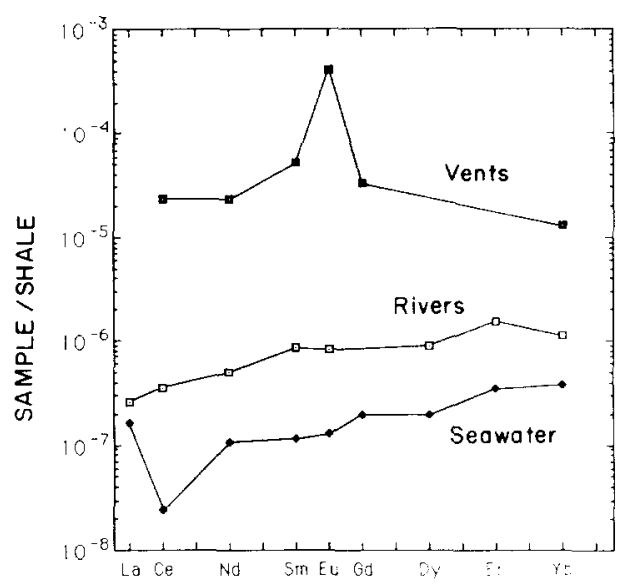

Fig. 1. The REE patterns of average seawater at $2.5 \mathrm{~km}$ depth, rivers (after estuarine removal), and end-member hydrothermal vent solutions. Note that seawater lacks the positive Eu anomaly expected from hydrothermal inputs. Data sources: Seawater and rivers from Goldstein and Jacobsen (1988, table 3); hydrothermal vents from Owen and Olivarez (1988, table 1), using data from Michard and Albarède (1986).

stein and Jacobsen (1988), who have argued that, if $\mathrm{Eu}$ is removed from solution at the same rate as its neighbors in the lanthanide series, then seawater should exhibit a positive Eu anomaly. For the sake of consistency with this argument, we have used identical values as those used by Goldstein and Jacobsen (1988) to construct the river and seawater REE patterns in Fig. 1. For the seawater pattern, Goldstein and Jacobsen (1988, table 3 ) estimated the REE concentration values by averaging measurements made by Elderfield and Greaves (1982), De Baar et al. (1983, 1985) and Klinkhammer et al. (1983) at five different stations and at a depth of $2.5 \mathrm{~km}$. The REE data for river inputs, which reflect estuarine removal processes, were taken from recent river data reported by Goldstein and Jacobsen (1988). Data for hydrothermal vents were taken from Michard and Albarède (1986) and represent a best estimate of the end-member vent fluid concentrations (see discussion in Owen and Olivarez, 1988).

An estimate of the relative contribution of 
Eu from hydrothermal vents versus rivers can be obtained by calculating a total REE flux from both of these sources. A lower boundary is based on the information reported in Goldstein and Jacobsen (1988), who calculate that hydrothermally derived Eu equals about 28\% of the river input. To obtain this value, they assumed: the effective dissolved load of Eu in river waters (i.e. the average concentration of $\mathrm{Eu}$ in river waters after estuarine removal processes ) is $1.04 \mathrm{ng} / \mathrm{kg}$; a global river water discharge of $4.2 \times 10^{19} \mathrm{~g} / \mathrm{yr}$; and a hydrothermal fluid flux of $2.9 \times 10^{16} \mathrm{~g} / \mathrm{yr}$. Their estimate for the average value of $\mathrm{Eu}$ in hydrothermal fluids is not stated explicitly, but they do report that this value was obtained by averaging REE concentration data for hydrothermal fluids at $13^{\circ} \mathrm{N}$ and $21^{\circ} \mathrm{N}$ from Michard et al. (1983) and Michard and Albarède (1986). Based on the above data and their estimate that the ratio of the Eu hydrothermal to river flux ratio is 0.28 , we calculate that they must have used a value of $421 \mathrm{ng} / \mathrm{kg}$ as the average concentration of $\mathrm{Eu}$ in hydrothermal fluids.

A significantly higher plume/river flux ratio can be obtained by using only those samples of hydrothermal fluids which are relatively pure, and a slightly lower value for the global river water discharge. Owen and Olivarez (1988) estimated the average REE concentrations in hydrothermal fluids from $13^{\circ} \mathrm{N}$ and $21^{\circ} \mathrm{N}$ by considering only those samples collected in $\mathrm{Ti}$ sample bottles by Michard and Albarède (1986), and among these, only those samples whose $\mathrm{Mg}$ concentrations suggest the recovery of a more than $90 \%$ pure hydrothermal fluid. These considerations result in a significantly higher value ( $518 \mathrm{ng} / \mathrm{kg}$ versus $421 \mathrm{ng} / \mathrm{kg}$ ) for the concentration of Eu (and other REE's) in hydrothermal fluids. Using this higher value for Eu, along with a lower estimate of the global river flux $\left(3.74 \times 10^{19} \mathrm{~g} / \mathrm{yr}\right.$; Martin and Meybeck, 1979), we calculate that the hydrothermal to river flux ratio for $\mathrm{Eu}$ is 0.39 , which is higher than the ratio $(0.28)$ reported by Goldstein and Jacobsen ( 1988 ). The values we cal- culate serve to augment the discrepancy in the predicted versus observed REE pattern of seawater discussed by Goldstein and Jacobsen, who used a more conservative estimate for the hydrothermal Eu flux.

Of all the parameters involved in making the flux comparisons, the greatest uncertainty is associated with the mass flux value of hydrothermal fluids. In general, the flow rate of seawater through the oceanic crust will depend on the convective heat flux anomaly, the average temperature of reaction, and the heat capacity of the fluid. An expression for the rate of hydrothermal circulation is given by (after Wolery and Sleep, 1976):

$$
\mathrm{HTF}=H /\left[C_{\mathrm{w}}\left(T_{2}-T_{1}\right)\right]
$$

where $\mathrm{HTF}=$ the hydrothermal fluid mass flux (g/yr); $H=$ the convective heat flow anomaly (cal./yr); and $T_{1}=$ average temperature of the entering fluid (approximately $3^{\circ} \mathrm{C}$ ); $T_{2}=$ average temperature of the exiting hydrothermal fluid $\left({ }^{\circ} \mathrm{C}\right) ; C_{\mathrm{w}}=$ the heat capacity of the fluid $\left(=1 \mathrm{cal} . /\left(\mathrm{g} /{ }^{\circ} \mathrm{C}\right)\right)$.

Estimates of this value span two orders of magnitude based on the ${ }^{3} \mathrm{He}$ content of hydrothermal fluids (Lupton et al., 1980; Michard et al., 1983) and the integrated ${ }^{3}$ He flux into seawater (Jenkins et al., 1978; Craig and Lupton, 1981), as discussed by Goldstein and Jacobsen (1987). Another uncertainty is concerned with the validity of using the helium data to estimate the amount of on-axis hydrothermal activity. Geophysical and geochemical studies suggest that as much as $80-90 \%$ of the total heat may be dissipated as off-axis hydrothermal circulation through sediments (see Wolery and Sleep, 1988, for a summary of these studies). An important consideration, however, is that because off-axis circulation occurs at lower temperatures, it requires a much higher mass flux of water to satisfy the convective heat anomaly than if all of the circulation occurred on-axis at higher temperatures. $\mathrm{Hy}$ - 
drothermally altered rocks from three off-axis drill sites represent reaction temperatures between $20^{\circ}$ and $80^{\circ} \mathrm{C}$ (Hart and Staudigel, 1978 , as cited in Wolery and Sleep, 1988). Assuming an average exit temperature of $50^{\circ} \mathrm{C}$ for off-axis circulation, a global convective heat flow anomaly of $50 \times 10^{18} \mathrm{cal}$. $/ \mathrm{yr}$ (Wolery and Sleep, 1988), and that $80 \%$ of hydrothermal circulation occurs off-axis, we estimate the mass flux of hydrothermal circulation to be 8.5 $\times 10^{17} \mathrm{~g} / \mathrm{yr}$. This represents a thirty-fold increase in the amount of seawater circulating through off-axis hydrothermal systems relative to the amount flowing through axial systems at an exit temperature of $350^{\circ} \mathrm{C}$. The chemical fluxes between seawater, sediments, and basalt at off-axis sites may be significant; however, they cannot be estimated from the data presently available. In this regard an important assumption of the Goldstein and $\mathrm{Ja}$ cobsen (1988) study is that the mass flux of REE's to seawater from both rivers and hydrothermal vents is additive, which implies that the Eu anomaly of seawater, for example, could be used to constrain the hydrothermal flux.

\subsection{REE scavenging by hydrothermal precipitates}

This discrepancy between the expected versus observed REE pattern of seawater is investigated in the present study by examining the fate of hydrothermally derived REE's in the marine system. We hypothesize that seawater does not exhibit a significant positive Eu anomaly because, relative to its neighbors in the lanthanide series, this element is preferentially removed (scavenged) from vent solutions by hydrothermal precipitates. As a first approximation, we suggest that the rate of removal is proportional to the REE concentration in the fluid phase, rather than at a rate proportional to atomic number. A simple quantitative model of this hypothesis is given by the following relationship:
$\mathrm{d}(C)_{\text {ReE-Scay. }} / \mathrm{d} t \propto(C)_{\text {ReE-fluid }}$

where $(C)_{\text {REE-Scav }}=$ the concentration of a particular REE scavenged by the hydrothermal precipitate; $(C)_{\text {REE-fluid }}=$ the concentration of a given REE in the fluid phase (seawater, hydrothermal solutions ); and $t=$ time.

This hypothesis implies that the scavenging of REE's by hydrothermal precipitates is nonspecific with respect to individual REE's, and that relatively large amounts of vent-derived $\mathrm{Eu}$ become incorporated into precipitates rather than seawater.

Earlier attempts to model chemical scavenging have been based on the one-dimensional vertical concentration profiles (Craig, 1974; Boyle et al., 1977; Measures and Edmond, 1982 ) of trace elements in seawater. However, the utility of these models for predicting the scavenged trace element flux to marine sediments, particularly with respect to the REE's, has not yet been adequately demonstrated. On the other hand, attempts to model scavenging processes based on the analysis of solid phases are complicated by the fact that marine sediments are typically multi-component systems comprised of lithogenous, biogenous, and hydrogenous phases. In the case of the REE's, it is especially difficult to determine how these elements are distributed among each of these phases. This problem has been minimized in the present study because Site 598 sediments represent a geochemically simple two-component system consisting of biogenous carbonates and hydrothermal precipitates (Ruhlin and Owen, 1986a). Palmer (1985) has demonstrated that the REE content of foraminiferal biogenic shell material is very low; consequently, the distribution of the REE's in Site 598 samples can be assumed to be associated exclusively with the hydrothermal component.

The behavior of REE's in Site 598 samples has been studied by Ruhlin and Owen (1986a, b) who report that hydrothermal precipitates are particularly effective scavengers of REE's from seawater. Their work also suggests that 
scavenging continues as a post-depositional process. Although REE mobilization during early diagenesis has been found in reducing nearshore sediments (Elderfield and Sholkovitz, 1987), Site 598 sediments, located in an open ocean environment, show minimal evidence of diagenetic alteration (Leinen et al., 1986). Hence, diffusion of REE's through pore waters is assumed to represent a negligible source. Plots of the REE content of the hydrothermal component versus distance from the paleorise axis (Fig. 2) show that the degree of scavenging is related to the distance which these precipitates have been carried away from the rise crest. However, because the time required for currents to carry hydrothermal pre-
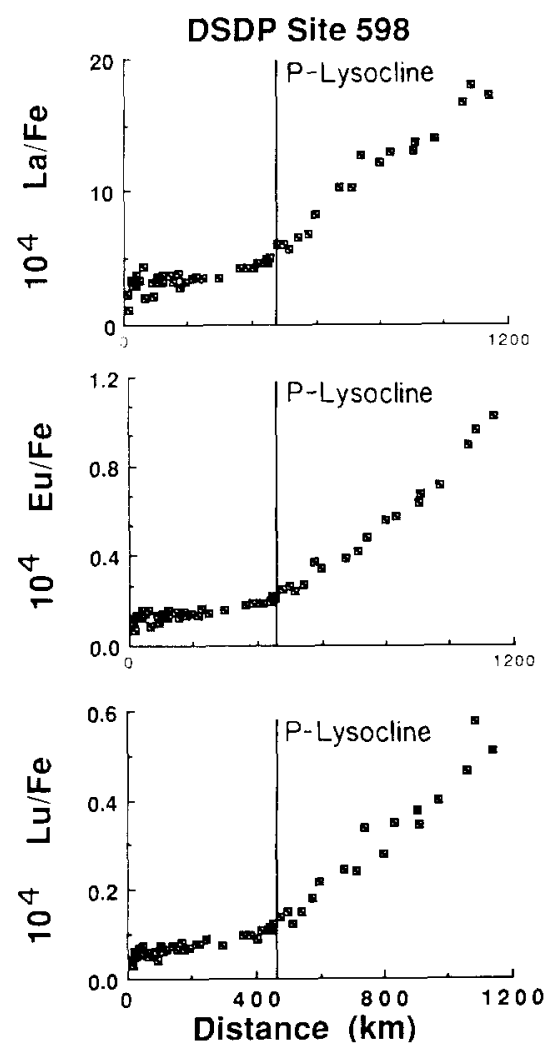

Fig. 2. Relationship between the REE/Fe concentration ratio in DSDP Site 598 hydrothermal sediments and the distance these precipitates have travelled away from the paleo-rise crest for three representative elements. In general, the REE content increases with increasing distance and there is a significant increase in REE uptake for precipitates deposited below the paleo-lysocline. cipitates to their farthest site of deposition (years or less) is much less than the burial time of these sediments (thousands of years), REE scavenging will primarily reflect the exposure of these precipitates to overlying seawater while at the sediment-water interface before their ultimate burial.

\subsection{Scavenging indices}

A suitable test of the hypothesis that $\mathrm{Eu}$ and other REE's are removed from solution (seawater) at a rate which is proportional to their concentration in the fluid requires a quantitative assessment of the relative degree of scavenging for each REE under consideration. This was achieved by calculating a "scavenging index" for each REE. This index is defined as the slope value obtained from the linear regression of the $\mathrm{REE} / \mathrm{Fe}$ ratio of hydrothermal sediments as a function of distance travelled away from the paleorise crest.

The justification for defining these indices is based on scatter plots of the type shown in Fig. 2. Here the $\mathrm{REE} / \mathrm{Fe}$ ratio in the hydrothermal component is plotted against distance travelled from the paleorise crest. The REE content of each sample was normalized to its iron content because previous investigations (Ruhlin and Owen, 1986a, b) of these samples have shown that the REE's are associated primarily with the Fe phases. The three plots shown in Fig. 2 are typical of those observed for all eight of the REE's under consideration. In general, the REE content of the hydrothermal phases increases with increasing distance away from the paleorise crest. Although the shape of each curve is non-linear over the entire distance range, as a first approximation, uptake of REE's can be modelled as linear with distance assuming the existence of two subpopulations. The first subpopulation, comprised of hydrothermal precipitates deposited be- 
tween 0 and $450 \mathrm{~km}$ from the paleorise crest, shows a relatively gradual increase in REE per unit distance, while the second subpopulation (those deposited beyond $450 \mathrm{~km}$ ) exhibits an enhanced increase in REE's. The rationale for defining two subpopulations is based on the fact that, for each plot, a change in the geological conditions occurs at this location $(450 \mathrm{~km})$ from the paleorise crest. Specifically, it represents the position of the paleolysocline determined for this site (Rea and Leinen, 1986). Due to the enhanced rate of carbonate dissolution, the downcore position of the paleolysocline reflects a significant change in the total sediment mass accumulation rate (MAR). Consequently, hydrothermal precipitates which were deposited at distances greater than $450 \mathrm{~km}$ from the paleorise crest, below the paleolysocline, were buried relatively slowly and exposed to seawater much longer compared to those deposited closer to the paleorise crest. Thus, the below-lysocline samples should have an overall higher REE content due to longer exposure to seawater. Linear sedimentation rates for the two sample groups range between $0.05-0.19 \mathrm{~cm} / \mathrm{yr}$ for the below-lysocline group and $0.31-0.81 \mathrm{~cm} / \mathrm{yr}$ for the above-lysocline group.

This line of reasoning was tested by examining the relationship between the $\mathrm{REE} / \mathrm{Fe}$ concentration ratio and the sample mass accumulation rate (MAR). MAR values are the product of the measured linear sedimentation rate (LSR) and the measured dry bulk density (see Leinen et al., 1986). If burial rates (i.e. relative exposure to seawater) have a negligible effect on the REE content of the two sample groups (above versus below lysocline), then no correlation should be found between these two variables. However, as shown in Fig. 3, an inverse relationship is observed, indicating that burial rates limit the degree to which hydrothermal precipitates scavenge REE's. (A similar pattern between these two variables, as shown in Fig. 3 for $\mathrm{Eu}$, is generally observed for all REE's.) Ruhlin and Owen (1986a, b)

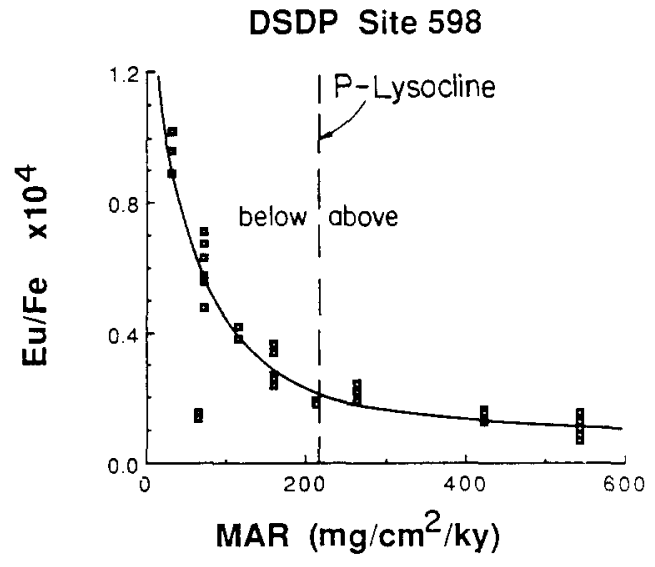

Fig. 3. Relationship between the REE/Fe ratio in Site 598 hydrothermal sediments and the sediment mass accumulation rate. The inverse correlation shown here for Eu implies that scavenging from seawater continues as a postdepositional process.

have reported that the REE content of Site 598 samples has not been affected by the remobilization of Fe and $\mathrm{Mn}$ in the sediment column; however, our results indicate that these samples have been affected by post-depositional REE scavenging from the overlying waters.

Because the REE content of Site 598 sediments has been influenced by the sediment mass accumulation rate, the samples were divided into two subpopulations representing an above and below lysocline sample group. As discussed earlier, this distinction simplifies the relationships observed for each scatter plot of the type shown in Fig. 2. Each subpopulation displays a linear relationship between the change in REE content of the hydrothermal precipitates $[\mathrm{d}(\mathrm{REE} / \mathrm{Fe})]$ per unit distance $(\mathrm{d} x)$ these precipitates have travelled away from the paleorise crest. That is, the slope value (Table I) of these line segments [d(REE/Fe)/ $\mathrm{d} x]$, reflects the combined effects of both distance and time on the scavenging process and is a quantitative measure of REE scavenging intensity by hydrothermal precipitates. Scavenging indices (slope values) and their statistical significance levels ( $p$ values) are reported in Table I for each REE in both sample groups. Such indices were also calculated using the age 


\section{TABLE I}

Scavenging indices (slope values $\times 10^{6}$ ), correlation coefficients $\left(r^{2}\right)$ and significance of correlations ( $p$ value) of Site 598 samples obtained by a least squares regression of the REE/ $\mathrm{Fc}$ concentration ratio in hydrothermal precipitates versus distance $(\mathrm{km})$ from the paleorise crest.

$\mathrm{REE} / \mathrm{Fe} \quad \begin{array}{ll}\left(\times 10^{\circ}\right) \\ \left(\times 1 r^{2}\right.\end{array} \quad$ pvalue

\begin{tabular}{|c|c|c|c|c|}
\hline \multicolumn{5}{|c|}{ thove $(1 \mathrm{soc}$ line $(9-475 \mathrm{~km})$ : } \\
\hline $\mathrm{Lia} / \mathrm{Fe}$ & 34 & 0.468 & 0.61 & 0.0000 \\
\hline $\mathrm{Ce} / \mathrm{Fc}$ & 28 & 0.167 & 0.61 & 0.0001 \\
\hline $\mathrm{Nd} / \mathrm{Fe}$ & 18 & 0.243 & 0.18 & 0.0753 \\
\hline $\mathrm{Sm} / \mathrm{Fe}$ & 34 & 0.0793 & 0.74 & 0.0000 \\
\hline $\mathrm{Eu} / \mathrm{Fe}$ & 34 & 0.0214 & 0.76 & 0.0000 \\
\hline $\mathrm{Tb} / \mathrm{Fe}$ & 34 & 0.0174 & 0.67 & 0.0000 \\
\hline $\mathrm{Yb} / \mathrm{Fe}$ & 34 & 0.0590 & 0.74 & 0.0000 \\
\hline $\mathrm{Lu} / \mathrm{Fe}$ & 34 & 0.0146 & 0.84 & 0.0000 \\
\hline \multicolumn{5}{|c|}{ Below lysoline $(500-1140 \mathrm{~km})$ : } \\
\hline $\mathrm{La} / \mathrm{Fc}$ & 16 & 1.88 & 0.96 & 0.0000 \\
\hline $\mathrm{Ce} / \mathrm{Fe}$ & 15 & 0.927 & 0.86 & 0.0000 \\
\hline $\mathrm{Nd} / \mathrm{Fe}$ & 9 & 1.76 & 0.65 & 0.0086 \\
\hline $\mathrm{Sm} / \mathrm{Fe}$ & 16 & 0.457 & 0.97 & 0.0000 \\
\hline $\mathrm{Eu} / \mathrm{Fe}$ & 16 & 0.117 & 0.97 & 0.0000 \\
\hline $\mathrm{Tb} / \mathrm{Fc}$ & 16 & 0.0866 & 0.94 & 0.0000 \\
\hline $\mathrm{Yb} / \mathrm{Fe}$ & 16 & 0.254 & 0.98 & 0.0000 \\
\hline $\mathrm{Lu} / \mathrm{Fe}$ & 16 & 0.0618 & 0.94 & 0.0000 \\
\hline
\end{tabular}

of the sample, instead of distance from the paleorise crest, as the independent variable. However, this substitution has no qualitative effect on the interpretations which are presented in the remainder of this paper, so, for the sake of convenience, we present our results using distance as the independent variable.

\subsection{Scavenging indices and fluid phase concentration}

The relationship between the calculated scavenging indices (Table I) and the average concentration of REE's in modern seawater (Høgdahl et al., 1968; De Baar et al., 1985) is shown in Fig. 4. Here we observe a positive linear relationship between these two variables for both the above and below lysocline sample groups ( $p$ value $=0.01,0.03$, respectively $)$. These correlations suggest that the intensity of REE scavenging by hydrothermal precipitates

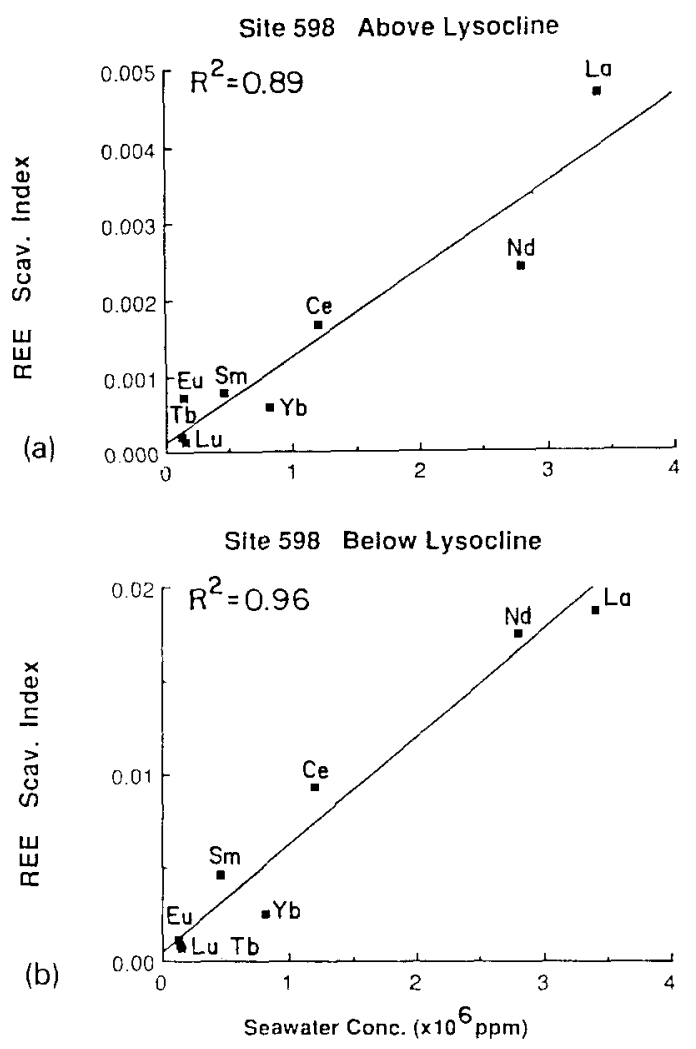

Fig. 4. Correlation between the calculated REE scavenging indices (Table I) and the average REE concentration in Pacific seawater for samples deposited above ( $p$ value $=0.001)$ and below the paleo-lysocline ( $P$ value $=0.003$ )

is primarily controlled by the concentration of REE's in the fluid phase, assuming that the scavenging agent is in abundant supply. Analyses of modern vent fluids from the Pacific indicate that the REE's are enriched by a factor of $10-10^{4}$ relative to average seawater concentrations (Michard and Albarède, 1986; Hinkley and Tatsumoto, 1987), whereas Fe is enriched by $10^{6}-10^{7}$ times ambient seawater values in these same fluids (Michard et al.. 1984; Von Damm et al., 1985; Philpotts et al., 1987). If these data are representative, we conclude that the process of REE removal in vents is still dominated by scavenging by Ferich hydrothermal precipitates.

An extrapolation of the correlation found 
between the calculated scavenging indices and seawater concentration predicts that REE scavenging rates are very high in hydrothermal plumes, especially for Eu. This is supported by field observations which show that seawater samples collected in the vicinity of hydrothermal vents (Klinkhammer et al., 1983) are actually depleted in REE's relative to ambient seawater at a comparable depth, as well as by sediment geochemistry data which show that the magnitudes of the $\mathrm{REE} / \mathrm{Fe}$ ratios in both proximal and distal hydrothermal sediments are much greater than those which characterize end-member hydrothermal plumes (Olivarez and Owen, 1987, 1989). In other words, scavenging by hydrothermal precipitates is sufficient to remove all of the vent-derived REE's in addition to REE's in the ambient seawater.

\subsection{Europium anomalies}

The Eu anomaly is characterized by a deviation of the shale-normalized concentration of Eu relative to its neighbors in the lanthanide series, assuming that the abundance of these elements varies in a linear fashion with increasing atomic number. Quantitatively, this has been calculated using the following formula:

Eu anomaly $=\log _{10}\left[\mathrm{Eu}^{*} /\left(\frac{2}{3} \mathrm{Sm}^{*}+\frac{1}{3} \mathrm{~Tb}^{*}\right)\right]$

where $\mathrm{Eu}^{*}, \mathrm{Sm}^{*}$, and $\mathrm{Tb}^{*}$ refers to the shalenormalized value of the REE in the sample. In the case of hydrothermal vent solutions, $\mathrm{Tb}$ data are not available: instead values which have been reported for Gd have been used and the equation was modified to reflect this substitution:

Eu anomaly $=\log _{10}\left[\mathrm{Eu}^{*} /\left(\frac{1}{2} \mathrm{Sm}^{*}+\frac{1}{2} \mathrm{Gd}^{*}\right)\right]$

If the rate of REE scavenging is proportional to the amount of REE's in the fluid phase, then the REE pattern of Fe-rich hydrothermal precipitates which initially form in the plume should exhibit a more positive Eu anomaly rel- ative to those which form after the plume has become diluted by seawater. That is, there should be a significant difference between the Eu anomalies of proximal and distal hydrothermal sediments. This hypothesis was tested by comparing the Eu anomaly values of Site 598 sediment samples with the two end-member values calculated for both seawater and hydrothermal vent solutions, and by examining the Eu anomaly values of these sediments as a function of their distance from the paleorise crest.

The average $\mathrm{Eu}$ anomaly of hydrothermal vent solutions from the East Pacific Rise (Michard and Albarède, 1986) is +1.00 . This value is based on end-member samples collected from $13^{\circ} \mathrm{N}$ (Eu anomaly $=+0.98$; average of samples $14 \mathrm{Ti} 2$ and $20 \mathrm{Ti} 4$ ) and from $21^{\circ} \mathrm{N}$ (Eu anomaly $=+1.03$; average of $\mathrm{HG}$ and OBS samples). The average Eu anomaly of seawater for the samples used in Fig. 1 is -0.082 . For comparison, we also calculated the Eu anomaly of Pacific seawater, where Site 598 samples are located, to account for interbasin variations which might be present. This value, obtained by using eight VERTEX II deep water samples (De Baar et al., 1985 ) collected between depths of 1000 and $3250 \mathrm{~m}$, is essentially zero $(+0.0002)$.

A plot of the Eu anomalies of Site 598 samples is shown in Fig. 5 as a function of their distance from the paleorise crest. In general, the $\mathrm{Eu}$ anomaly values of these samples range between +0.01 and +0.13 and are enriched relative to the global average values $(-0.082)$ and to Pacific seawater (Eu anomaly= $+0.0002)$. This plot also suggests that this enrichment is due to scavenging from a plume source as evidenced by the relative change in these values with increasing distance from the paleorise crest. In general, these values decrease and become more "seawater like" away from the ridge axis and more plume like closer to the axis. The fact that the Eu anomaly values of the samples closest to the paleoridge axis do not equal the value for end-member vent 


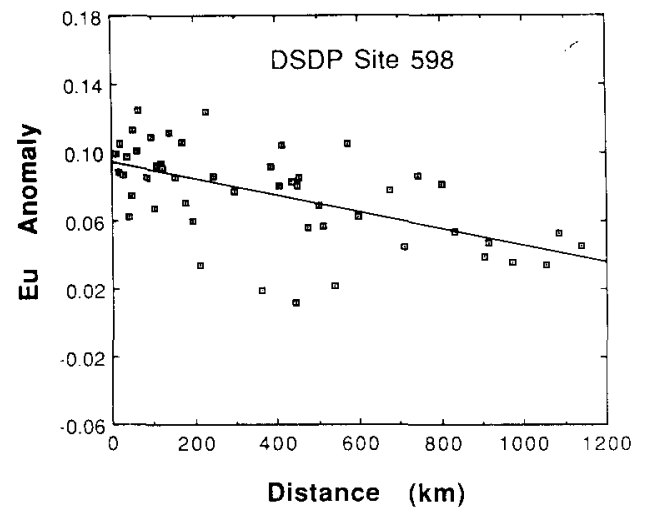

Fig. 5. Eu-anomaly values of Site 598 hydrothermal sediments as a function of their distance away from the paleorise crest. In general, these values are more "plume-like" closer to the paleo-ridge axis and become more seawaterlike away from the axis, suggesting a continuous "overprinting" of an initial plume REE signature with increasing exposure to seawater.

solutions is not surprising given the fact that these samples represents deposition $9 \mathrm{~km}$ away from the injection site. An original plume signature would likely be attenuated by continued scavenging from seawater.

Eu anomaly values for nearly "pure" proximal hydrothermal sediments (i.e. minimal seawater contamination) were calculated for sediments recovered from the Red Sea Deeps (Courtois and Treuil, 1977; Oudin and Cocherie, 1988). The REE patterns of these samples have been interpreted as being derived from a predominantly hydrothermal source; therefore, their Eu anomaly values can be used to estimate an upper bound for hydrothermal precipitates which have been exposed to relatively high hydrothermal inputs. Relative to Site 598 , located in the open ocean, the Red Sea Deeps have been shielded from exposure to normal seawater due to the stability of very dense hydrothermal brines which are found within these deeps. Although these samples reflect enhanced exposure to the hydrothermal fluids, their Eu anomaly values are nonetheless attenuated relative to the predicted endmember Eu anomaly value for vents. For example, Eu anomaly values for samples from the Atlantis II Deep range between +0.32 and
+0.55 . In a comparative sense, it is reasonable to expect that Site 598 samples would exhibit lower Eu anomaly values, and in this regard the Eu anomaly data may indeed reflect the combined effects of an initial plume signature which was subsequently overprinted by seawater-derived REE's. This hypothesis is supported by the behavior of REE's in vent particulates along the Mid-Atlantic Ridge (German et al., 1990).

\section{Conclusions}

The impact of seafloor hydrothermal activity upon the REE geochemistry of seawater depends upon the removal efficiency of these elements once the hydrothermal fluid is debouched onto the seafloor. Assuming that the removal rate of $\mathrm{Eu}$ is the same as its neighbors. then Goldstein and Jacobsen (1988) have suggested that the REE pattern of seawater should exhibit a positive Eu anomaly due to the high $\mathrm{Eu}$ concentrations in hydrothermal vents. Based on the scavenging indices calculated for Site 598 sediments, our study indicates that this assumption is not valid. We propose that, as a first approximation, the REE's are scavenged from solution at a rate proportional to their concentration in the fluid phase and, as previously reported by Olivarez and Owen (1989). seafloor hydrothermal activity acts as a net sink for REE's in seawater. Thus, for the modern case, $\mathrm{Eu}$ is predicted to be disproportionately removed from hydrothermal fluids relative to its neighbors.

An examination of the Eu anomaly values of Site 598 sediments indicate two primary sources of REE's: seawater and hydrothermal vents. The variation in the Eu anomaly values with distance from the paleorise crest suggests that an initial plume-like REE signature, which is most evident for samples closest to the paleorise crest, is achieved shortly after the fluids 
debouch onto the seafloor. This signature is then "overprinted" with REE's subsequently scavenged from seawater. From these results we conclude that the Eu anomaly of seawater is not a good proxy indicator for constraining the hydrothermal fluid flux because $\mathrm{Eu}$ and the other REE's are rapidly removed from this system. Thus, there is no reason to think that the REE measurements which have been reported thus far for hydrothermal vents are not representative of typical end-member solutions, or that the estuarine removal rates for the REE's other than Eu (Goldstein and Jacobsen, 1988) are too high.

\section{Acknowledgements}

The sediment samples used in this study were obtained during the 1983 cruise of the Glomar Challenger, sponsored by the Deep Sea Drilling Project of the National Science Foundation. We thank the crew members of these vessels and our colleagues who were members of the scientific parties on these cruises for their invaluable assistance in obtaining these samples. This research was supported in part by the National Science Foundation under Grant No. OCE-8410034, the U.S. Bureau of Mines under Grant No. G1 185128 (MMTC-89-3), and the Michigan Sea Grant College Program under Grant Nos. NA85A-D-SG045 and NA86AA-D-SG043. We are grateful to A. Lasaga and anonymous reviewers for comments and suggestions they offered based on a review of an earlier version of this paper.

\section{References}

Boyle, E.A., Sclater, F.R. and Edmond, J.M., 1977. The distribution of dissolved copper in the Pacific. Earth Planet. Sci. Lett., 37: 38-54.

Campbell, A.C.. Palmer, M.R., Klinkhammer, G.P., Bowers, T.S., Edmond, J.M., Lawrence, J.R., Casey, J.F., Thompson, G., Humphris, S., Rona, R. and Karson, J.A.. 1988. Chemistry of hot springs on the MidAtlantic Ridge. Nature (London), 335: 514-519.

Courtois, C. and Treuil. M., 1977. Distribution des terres rares et de quelques elements en trace dans les sédi- ments récents des fosses de la Mer Rouge. Chem. Geol., 20: $57-72$.

Craig, H., 1974. A scavenging model for trace elements in the deep sea. Earth Planet. Sci. Lett.. 23: 149-159.

Craig, H. and Lupton, J.E.. 1981. Helium-3 and mantle volatiles in the ocean and the oceanic crust. In: C. Emiliani (Editor), The Sea, Vol. 7. Wiley, New York. N.Y., pp. 391-428.

Dams, R. and Robbins, V.A., 1970. Nondestructive activation analysis of environmental samples. Univ. Michigan, Great Lakes Research Div.. Ann Arbor, Mich., Tech. Rep. No. 48.

De Baar, H.J.. Bacon, M.P. and Brewer, P.G., 1983. Rareearth distributions with a positive $\mathrm{Ce}$ anomaly in the Western North Atlantic Ocean. Nature (London), 301: 324-327.

De Baar, H.J., Bacon, M.P., Brewer, P.G. and Bruland, K.W., 1985. Rare earth elements in Pacific and Atlantic Oceans. Geochim. Cosmochim. Acta. 49: 19431959.

Elderfield, H. and Greaves, M.J., 1982. The rare earth elements in seawater. Nature (London), 296: 214-219.

Elderfield, H. and Sholkovitz. E.R., 1987. Rare earth elements in the pore waters of reducing nearshore sediments. Earth Planet. Sci. Lett.. 82: 280-288.

Fleet, A.J., 1984. Aqueous and sedimentary geochemistry of the rare earth elements. In: P. Henderson (Editor), Rare Earth Element Geochemistry. Elsevier, Amsterdam, pp. 343-373.

Fox, D.J. and Guire. K.E., 1976. Documentation for MIDAS. The Statistical Research Laboratory, Univ. Michigan, Ann Arbor, Mich., 3rd ed.

German, C.R., Klinkhammer, G.P., Edmond. J.M., Mitra, A. and Elderfield, H. 1990. Hydrothermal scavenging of rare-earth elements in the ocean. Nature (London), 345: 516-518.

Goldstein, S.J. and Jacobsen, S.B., 1987. The Nd and Sr isotopic systematics of river-water dissolved material: Implications for the sources of $\mathrm{Nd}$ and $\mathrm{Sr}$ in seawater. Chem. Geol., 66: 245-272.

Goldstein. S.J. and Jacobsen, S.B., 1988. Rare earth elements in river waters. Earth Planct. Sci. Lett.. 89: 3547.

Gordon, C.E., Randle, K.. Goles, G.D.. Corliss, J.B., Beesen, M.H. and Oxley, S.S., 1968. Instrumental activation analysis of standard rocks with high resolution $\mathrm{X}$ ray detectors. Geochim. Cosmochim. Acta, 32: 364396.

Hart. S.R. and Staudigel. H., 1978. Ocean crust: Age of hydrothermal alteration. Geophys. Res. Let1.. 5: 10091012.

Hinkley, T.K. and Tatsumoto, M.. 1987. Metals and isotopes in Juan de Fuca Ridge hydrothermal fluids and their associated solid materials. J. Geophys. Res., 92: 1943-1959.

Høgdahl, O.T., Melsom, S. and Bowen, V.T., 1968. Neutron activation of lanthanide elements in seawater. Adv. Chem. Ser., 73: 308-325. 
Hoyle. J., Elderfield, H., Gledhill, A. and Greaves, M., 1984. The behavior of the rare earth elements during mixing of river and sea waters. Geochim. Cosmochim. Acta, 48: 143-150.

Jenkins, W.J., Edmond, J.M. and Corliss, J.B., 1978. Excess ${ }^{3} \mathrm{He}$ and ${ }^{4} \mathrm{He}$ in Galapagos submarine hydrothermal waters. Nature (London), 272: 156-158.

Keasler, K.M. and Loveland, W.D, 1982. Rare earth elemental concentrations in some Pacific Northwest riv. ers. Earth Planet. Sci. Lett., 61: 68-72.

Klinkhammer, G., Elderfield, H. and Hudson, A., 1983. Rare earth elements in seawater near hydrothermal vents. Nature (London), 305: 185-188.

Leinen, M., Rea, D.K.. et al., 1986. Site 598. Initial Reports of the Deep Sea Drilling Project, Vol. 92. U.S. Gov. Print. Off., Washington. D.C., pp. 97-116.

Lupton, J.E.. Klinkhammer, G.P., Normark, W.R.. Hayman. R., Macdonald, K., Weiss, R. and Craig. H., 1980. Helium-3 and manganese at the $21^{\circ} \mathrm{N}$ EPR hydrothermal site. Earth Planet. Sci. Lett., 50: 115-127.

Martin. J-M. and Meybeck. M., 1979. Elemental massbalance of material carried by major world rivers. Mar. (hem.. 7: 173-206.

Martin. J.M., Høgdahl, O. and Philippot, J.C., 1976. Rare earth element supply to the oceans. J. Geophys. Res., 81:3119-3124

Measures, C.I. and Edmond, J.M., 1982. Beryllium in the water column of the central North Pacific. Nature (London). 297: 51-53.

Michard. A. and Albarède, F., 1986. The REE content of some hydrothermal fluids. Chem. Geol., 55: 51-60.

Michard, A., Albarède. F., Michard, G., Minster, J.F. and Charlou, J.L.. 1983. Rare earth elements and uranium in high-temperature solutions from East Pacific Rise hydrothermal vent field $\left(13^{\circ} \mathrm{N}\right)$. Nature (London), 303: 795-797.

Michard, G.. Albarède. F., Michard, A., Minster, J.-F., Charlou, J.L. and Tan, N., 1984. Chemistry of solutions from the 13 N East Pacific Rise hydrothermal site. Earth Planet. Sci. Lett., 67: 297-307.

Olivarez, A.M. and Owen. R.M., 1987. Scavenging and mass accumulation of REE in Pacific hydrothermal precipitates. Eos (Trans. Am. Geophys. Union), 68: 1326 (abstract).

Olivarez, A.M. and Owen. R.M., 1989. REE/Fe variations in hydrothermal sediments: Implications for the
REE content of seawater. Geochim. Cosmochim. Acta. 53: 757-762.

Oudin. E. and Cocherie, A., 1988. Fish debris record the hydrothermal activity in the Atlantis II Ieep sediments (Red Sea). Geochim. Cosmochim. Acta, 52: $177-184$.

Owen. R.M. and Olivarez. A.M., 1988. Geochemistry of rare earth elements in Pacific hydrothermal sediments. Mar. Chem., 25: 1833-196.

Palmer, M.R., 1985. Rare earth elements in foraminifera tests. Earth Planet. Sci. Lett. 73: 285-298.

Philpotts. J.A., Aruscavage, P.J. and Von Damm, K.L., 1987. Uniformity and diversity in the composition of mineralizing fluids from hydrothermal vents on the Southern Juan de Fuca Ridge. J. Geophys. Res., 92: $11327-11333$

Piper, D.Z., 1974. Rare earth elements in the sedimentary cycle: A summary. Chem. Geol. 14: 285-304.

Rea, D.K. and Leinen. M., 1986. Crustal subsidence and calcite deposition in the South Pacific Ocean. In: M. Leinen, D.K. Rea, et al. (Editors). Initial Reports of the Deep Sea Drilling Project, Vol. 92. U.S. Gov. Prin1. Off.. Washington. D.C., pp. 299-303.

Ruhlin, D.E. and Owen, R.M.. 1986a. The rare earth element geochemistry of hydrothermal sediments from the East Pacific Rise: Examination of a seawater scavenging mechanism. Geochim. Cosmochim. Acta, 50: 393400.

Ruhlin. D.E. and Owen. R.M.. 1986b. Factors influencing the rare earth element composition of hydrothermal precipitates, East Pacific Rise. In: M. Leinen, D.K. Rea. et al. (Editors), Initial Reports of the Deep Sta Drilling Project, Vol. 92. U.S. Gov. Print. Off., Washington, D.C.. pp. 383-389.

Von Damm. K.L., Edmond, J.M.. Grant, B., Measures, C.I., Walden. B. and Weiss, R.F.. 1985. Chemistry of submarine hydrothermal solutions at $21^{\circ} \mathrm{N}$. East Pacific Rise. Geochim. Cosmochim. Acta. 49: 2197-2200.

Wolery, T.J. and Sleep, N.H. 1976. Hydrothermal circulation and geochemical flux at mid-ocean ridges. I. Geol., 84 (3): 249-275.

Wolery. T.J. and Steep, N.H., 1988. Interactions of Geochemical Cycles With the Mantle. In: C.B. Gregor. R.M. Garrels. F.T. Mackenzie and J.B. Maynard (Editors), Chemical Cycles in the Evolution of the Earth. Wiley, New York, N.Y., 276 pp. 